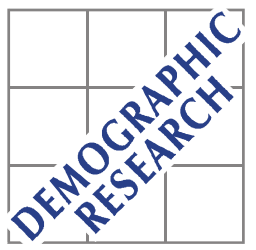

Demographic Research a free, expedited, online journal

of peer-reviewed research and commentary in the population sciences published by the Max Planck Institute for Demographic Research

Konrad-Zuse Str. 1, D-18057 Rostock · GERMANY

www.demographic-research.org

DEMOGRAPHIC RESEARCH

VOLUME 18, ARTICLE 10, PAGES 285-310

PUBLISHED 18 APRIL 2008

http://www.demographic-research.org/Volumes/Vol18/10/

DOI: $10.4054 /$ DemRes.2008.18.10

Research Article

\title{
What can we learn from indirect estimations on mortality in Mongolia, 1969-1989?
}

\section{Thomas Spoorenberg}

(C) 2008 Spoorenberg.

This open-access work is published under the terms of the Creative Commons Attribution NonCommercial License 2.0 Germany, which permits use, reproduction \& distribution in any medium for non-commercial purposes, provided the original author(s) and source are given credit.

See http:// creativecommons.org/licenses/by-nc/2.0/de/ 


\section{Table of Contents}

1 Introduction 264

2 Mongolian population censuses in the $20^{\text {th }}$ century 265

$2.1 \quad$ Quality of censuses 268

$3 \quad$ Census-based indirect mortality estimations 270

$3.1 \quad$ Variable $r$ method 271

3.2 Cumulation and projection technique for intercensal mortality 275

$4 \quad$ Comparison between indirect methods $\quad 277$

$5 \quad$ Confrontation of indirect estimates with direct mortality computed 279 from civil registration data

6 Putting Mongolian health situation in perspective 282

7 Conclusion 284

8 Acknowledgements 285

$\begin{array}{ll}\text { References } & 286\end{array}$ 


\title{
What can we learn from indirect estimations on mortality in Mongolia, 1969-1989?
}

\author{
Thomas Spoorenberg $^{1}$
}

\begin{abstract}
The closure of Mongolia to the international community during the $20^{\text {th }}$ century resulted in a dearth of available data and analytic demographic studies. In the absence of mortality analysis during the socialist period, this paper proposes the use of indirect census-based techniques to estimate mortality levels and trends of the last two socialist decades (1969-1989). Due to census data quality and choice of model life table, results are not homogeneous. The respective effects of these two components are discussed in order to understand the results. However, despite these shortcomings, it is shown that during the last socialist decades in Mongolia, the health conditions of the population deteriorated. The Mongolian pattern is relatively similar to the situation documented for the ex-socialist republics. Causes of this similarity are discussed.
\end{abstract}

\footnotetext{
${ }^{1}$ Thomas.Spoorenberg@metri.unige.ch
} 


\section{Introduction}

In 1921, the Mongol Ardyn Huv'sgalt Nam (MAHN) - the Mongolian People's Revolutionary Party - along with Soviet Russian support, proclaimed the independence of Mongolia from Chinese rule. ${ }^{2}$ In 1924, Mongolia adopted its first constitution instituting a People's Republic, becoming the first nation of the world (after the founders of the USSR (Russia, Ukraine, Belarus, and Transcaucasia)) to choose a socialist way of development. Since then, Mongolia's destiny has been closely linked to the USSR. Until 1991, its 70-years experience of socialist political and economic systems resulted in the closure of the country to the international community. The relative inaccessibility of demographic information and data resulted in a dearth of knowledge about demographic evolution during Mongolia's socialist period. However, in order to answer and foresee the needs of the centralized and planned economy, population has been considered a central variable by the successive socialist governments. The knowledge of national and regional population growth, population repartition by residence (urban-rural), and economic characteristics of population were prerequisites for the orientation of the Mongolian People Republic's development (Neupert 1996). During the past century, Mongolia conducted 9 population censuses: in 1918, 1935, 1944, 1956, 1963, 1969, 1979, 1989 and 2000. With the openness (il tod Mongolian glasnost) and restructuration (öörchlön baiguulalt - Mongolian perestroika) of the country during the $1980 \mathrm{~s},{ }^{3}$ Mongolian demographic data have been more easily available, enabling demographic analysis of the socialist period.

Surprisingly, the large amount of data collected by the National Statistical Office of Mongolia has been underused. In fact, as Neupert states (1996: 24), "[s]tudies on the population dynamics of the country or on relationships between socio-economic and demographic variables have never been conducted. The huge amount of population data accumulated since the 1950s has never been used for any analytical purpose."

Hence, the aim of this paper is to propose the use of population censuses to appraise through indirect estimation techniques, mortality levels and trends during the country's last decades of its socialist period.

Among the few demographic studies on Mongolian socialist and post-socialist periods, mortality has not been a subject of intense attention. Studies conducted on mortality in Mongolia have focused exclusively on young age or maternal mortality, using mostly survey data (for early-age, Dashtseren 2002, Neupert 1995, Pandey 1997;

\footnotetext{
${ }^{2}$ After having ruled the largest empire known in world history under the reign of Genghis Khan in the $13^{\text {th }}$ century, Mongolia has been the vassal of the Chinese Qing dynasty (1644-1911) for more than 200 years (Bawden 1989).

${ }^{3}$ These two movements were launched at the $19^{\text {th }}$ Party Congress of the Mongol Ardyn Huv'sgalt Nam (the Mongolian People’s Revolutionary Party) in 1986 (Kaplonski 2003: 4).
} 
for maternal mortality, Janes and Chuluundorj 2004). In fact, little is known about general mortality levels and trends in Mongolia, both during and after the socialist era. Usually, in international comparisons, Mongolia - which is included in East Asia according to convention - is never taken into account due to lack of reliable detailed information (Zhao and Kinfu 2005).

After introducing national population censuses in the past century, demographic analysis is employed to evaluate their quality. The paper then turns to the application of indirect techniques to estimate mortality levels and trends for the socialist period, prior to the political and economic transitions of the 1990s. Variable $r$ method and projection and cumulation technique are applied. Since both methods require only an age distribution from two censuses, intercensal mortality could be estimated and then compared. The results and limits of both methods are addressed. The indirect estimates are then confronted to direct method, based on vital registration data. The indirect results are of rather good quality. If the 'real' level of mortality is not given by the two indirect methods (but comprised between the two), the sketched trend is likely to be real. It is shown that Mongolia presents a rather similar mortality experience as the former socialist countries of both the USSR and Eastern Europe, with deterioration in population's health conditions. The Mongolian experience is discussed in light of the experience of the former socialist countries. To conclude, limitations and formulation of research that needs to be undertaken are addressed. The focus is on the last two decades of the Mongolian socialist era (1969-89); reasons of this choice are discussed further in the paper.

\section{Mongolian population censuses in the $20^{\text {th }}$ century}

Over the past century, the population of Mongolia has been recorded 9 times (Table 1), yet data homogeneity and comparison between censuses are not assured. In fact, the 1918, 1935 and 1944 census data are not presented by five-year age groups excluding henceforth comparison with subsequent operations (NSO 2003). These obstacles could have been easily overcome if original census data were available. But, it seems the original forms have been destroyed, ${ }^{4}$ and they are in Uighur-Mongolian. ${ }^{5}$ Moreover,

\footnotetext{
${ }^{4}$ To note, Neupert reports that "the results of the 1979 population census, which were stored on computer tapes, were erased in order to use tapes to store the results of the 1989 results.” (1996: 26, note 9).

${ }^{5}$ The Mongol bichig (literally, Mongol writing), the classical vertical script, was officially abandoned on the $25^{\text {th }}$ March 1941 in favor of a slightly modified Cyrillic alphabet (after unsuccessful attempts to introduce the Roman alphabet in the 1930s and in 1940) (Legrand, 1997). However, the transfer to Cyrillic was completed only in the 1950s (Atwood 2004). In 1991, following political democratic movements of 1989-90, the government wanted to reintroduce the Uighur-Mongolian alphabet as the official alphabet by 1994 - the Cyrillic alphabet being seen as a relic of the former Soviet domination- , but faced (continued on next page)
} 
the reliability of the first three censuses is doubtful since they had been conducted at times of important socio-political effervescences. ${ }^{6}$

Table 1: Date, total population and average annual growth rate, Mongolian censuses

\begin{tabular}{lrc}
\hline Date & Total Population & Average annual growth rate (per cent) \\
\hline Population Census & 647.5 & - \\
1918 & 738.2 & 0.8 \\
1 June 1935 & 759.1 & 0.3 \\
15 October 1944 & 845.5 & 0.9 \\
5 February 1956 & 1017.1 & 2.7 \\
1 May 1963 & & \\
Population and Housing Census & 2.8 \\
10 January 1969 & 1197.6 & 2.9 \\
5 January 1979 & 1595.0 & 2.5 \\
5 January 1989 & 2044.0 & 1.4 \\
5 January 2000 & 2373.5 & \\
\hline
\end{tabular}

Source: NSO 2003: 85-86.

Figure 1 presents the age and sex composition of Mongolian population at the six last censuses (1956-2000). The pyramids are in numbers, allowing to see at a glance the increase of Mongolian population size through the years and whether age and sex structures are marked by irregularities - indicating the effects of migration or any disturbing events such as war or epidemic. Since the mid-20 ${ }^{\text {th }}$ century, Mongolian population experienced important changes both in terms of size and composition. Over 50 years, passing through stages of the demographic transition, the population tripled from 845.5 thousand in 1956 to 2373.5 thousand in 2000 and its age composition transformed. ${ }^{7}$ The main increase took place during the 1960s, 1970s and 1980s, with mean annual growth rates attaining more than 2.5 percent (Table 1 ).

passive population resistance. In 1996, the Cyrillic script was reconfirmed as the official script (Atwood 2004).

${ }^{6}$ The 1910s are marked by the Independence of Mongolia from China and the proclamation of the Bogd Khaan monarchy; the 1930s by the reinforcement of communism and political and religious purges; the 1940s by World War II during which Mongolian soldiers fought in Soviet armies. (see details on these points in Baabar 2005, Bawden 1989). For example, the 1918 census is not complete, since a large part of the population was not covered by the census (Maiskii 1959, cited in NSO 2003: 38).

${ }^{7}$ With a substantial fertility reduction between 1989 and 2000 implying since then a process of population aging. 
Figure 1: Population pyramids of Mongolia (numbers), census year, 1956-2000
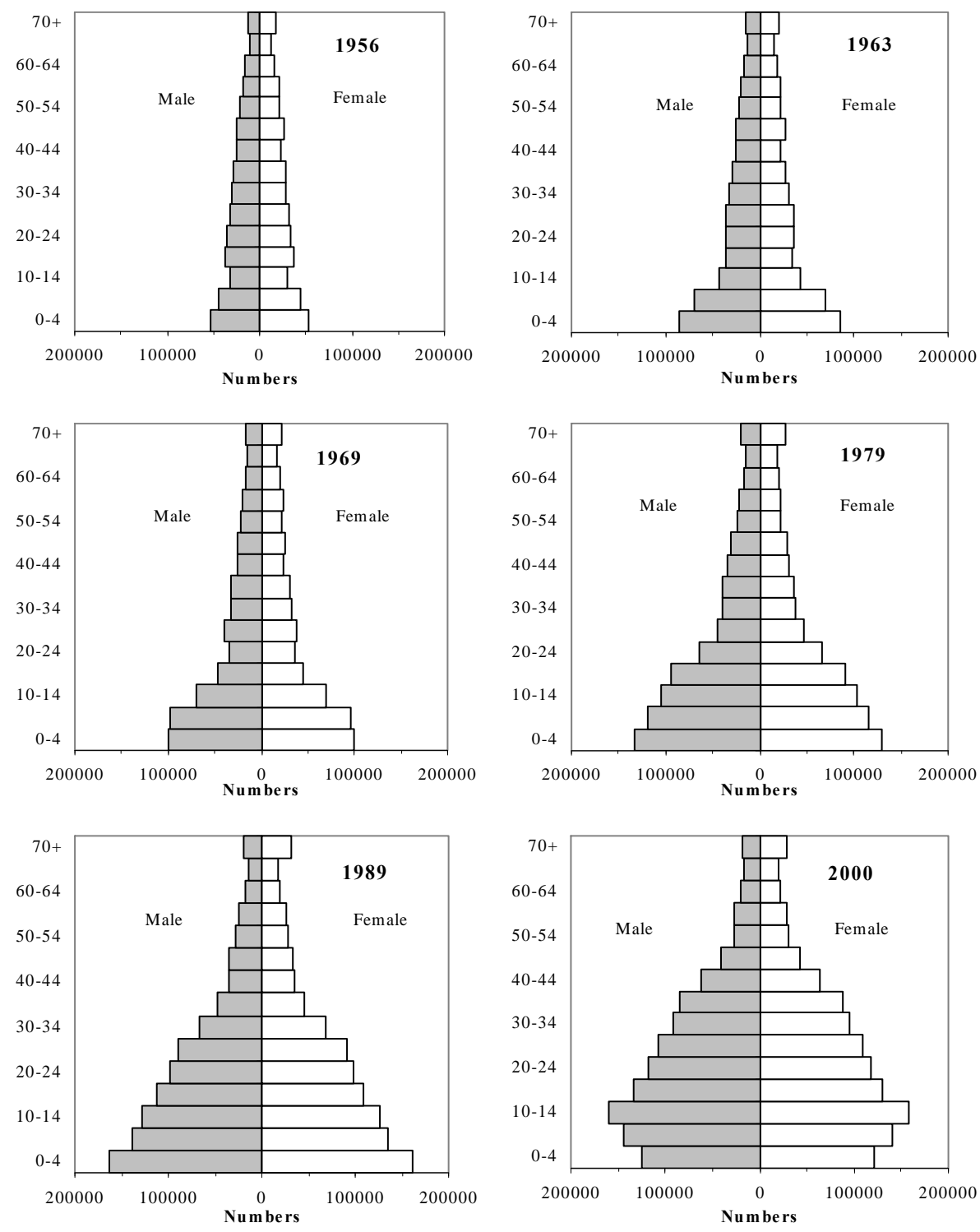

Source : NSO $2003: 85-86$ 
In 1956, the population pyramid is almost rectangular. This shape is the result of the high mortality which prevailed during the first part of the century ${ }^{8}$ and which is related to both the epidemiological environment, political repression of the 1930s, and the effects of World War II. Because of demographic inertia, this rectangular profile disappears only progressively throughout the censuses as mortality transition is underway. Since 1963, and until 1989, in addition to the decline in mortality, the expansion of the base of the pyramid bears out an increase in fertility. Thanks to imported western medicine (from the USSR), socio-economic development and governmental pro-natalist policies, the surviving proportion in all age groups rises and especially the proportion of surviving children (Neupert 1996). The 1989 pyramid presents a very young profile with a broad base, triangular shape indicating very high proportions in young age groups. The last decade of the century witnesses an impressive fertility reduction coinciding with the transition towards a market-oriented economy.

\subsection{Quality of censuses}

Demographic analysis, as a means to evaluate population age and sex structure, is well developed. Various methods exist to assess age and sex data quality (age ratio score, sex ratio score, age-heaping index (Whipple, Myers), United Nations age-sex accuracy index, population projection, etc.). Since mortality will be estimated through indirect techniques based on intercensal analysis, an appropriate option to check consistency of two successive censuses is intercensal cohort analysis. As the data are by five-year age groups and that correspondence from one census to the other has to be satisfied, this method of evaluation of data consistency can only be applied to censuses apart from 5 or 10 years $^{9}$ and when net migration is assumed to be negligible.

This method is only relevant for 1969, 1979 and 1989 Mongolian censuses. It is inappropriate for the previous censuses $(1956,1963)$, since the length of the intercensal period is not 5 or 10 years (but respectively 7 years (1956-63) and 6 years (1963-69)). Thus, only the last two decades of the socialist period (1969-89) will be observed here.

As for net migration, Mongolia was closed for decades. With the centralized system, internal and external migrations were highly controlled. Hence, according to

\footnotetext{
${ }^{8}$ Mortality transition in Mongolia can be considered to date from the end of the 1940s, beginning of the 1950s (Riley 2005).

${ }^{9}$ If population is by single year of age, this prerequisite can be ignored.
} 
Neupert (1992, 1996), international migration could be considered as insignificant during the country's socialist period. ${ }^{10}$

All the census counts (1969, 1979 and 1989) are based on the enumeration of the resident population of Mongolia (de-jure). Since the census dates are slightly different, the 1969 enumerated population is adjusted to an exact number of years. The 1969 population is moved backward in order to approximate the population at the $5^{\text {th }}$ January 1969, defining hence an exact 10-year interval and removes the effect induced by population growth on the intercensal survivorship estimates.

Intercensal cohort analysis to detect under-enumeration considers the proportion of a cohort of a given sex reported in a census who is counted in a later census. Here, the proportion of the people surviving at each age between 1969 and 1979 is calculated by dividing the 1979 population at a given age by the 1969 population of 10 years younger. The same applies between 1979 and 1989. In the absence of net international migration, proportions of surviving people exceeding 1.00 are spurious and point either to understatement in the first census or overstatement in the later one.

Table 2 shows the proportion of surviving people in each age group. In general, census quality is good with most surviving proportions lower than 1.00. But there are some striking irregularities. Both sexes exhibit similar survival ratios higher than 1.00 for the 0-4 age group in 1969-79 and for young adult age groups in both periods. Survival ratios higher than 1.00 are impossible if the age data are accurate and the population was indeed closed to migration. Such ratios indicate data inconsistency.

These patterns are typical of population undercount found in other populations both in less- and well-developed countries (Anderson 2004). The age group 10-14 is enumerated more completely than the $0-4$; and those aged 10-14 are enumerated more completely than those in their early twenties; and those in their thirties are enumerated more completely than those in their twenties (and even those aged 40-44 are enumerated more completely for males in 1979). In Mongolia, these patterns are generally comparable for males and females, but they are more important for the former than the latter and more salient in the 1969-79 intercensal cohort analysis.

Based on graphical examinations, different smoothing techniques have been tested (Arriaga et al. 1994). A soft smoothing has finally been applied to adjust the Mongolian data. ${ }^{11}$ However, even if intercensal cohort survival profiles improve, the smoothing does not erase all data inconsistencies (especially for males).

\footnotetext{
${ }^{10}$ It is worthwhile to note that for the recent period (1989-2000), precise data on international migration are not available. International migration is therefore assessed through the comparison of the 1989 and 2000 censuses (NSO 2002: 16).

${ }^{11}$ Smoothing technique smooth the data, but do they bring us any closer to the true age distribution?
} 
Table 2: Intercensal cohort analysis by sex, 1969, 1979 and 1989 censuses of Mongolia

\begin{tabular}{|c|c|c|c|c|c|}
\hline \multirow{3}{*}{$\begin{array}{l}\text { Age group in } \\
\text { first census } \\
(x, x+5)\end{array}$} & \multirow{3}{*}{$\begin{array}{l}\text { Age group in } \\
\text { second census } \\
(x, x+5)\end{array}$} & \multicolumn{4}{|c|}{ Intercensal cohort analysis } \\
\hline & & \multicolumn{2}{|c|}{$1969-79$} & \multicolumn{2}{|c|}{$1979-89$} \\
\hline & & Male & Female & Male & Female \\
\hline $0-4$ & $10-14$ & 1.053 & 1.035 & 0.967 & 0.973 \\
\hline $5-9$ & $15-19$ & 0.961 & 0.938 & 0.944 & 0.942 \\
\hline $10-14$ & $20-24$ & 0.917 & 0.955 & 0.931 & 0.957 \\
\hline $15-19$ & $25-29$ & 0.976 & 1.059 & 0.945 & 1.003 \\
\hline $20-24$ & $30-34$ & 1.137 & 1.064 & 1.046 & 1.034 \\
\hline $25-29$ & $35-39$ & 1.011 & 0.954 & 1.023 & 0.977 \\
\hline $30-34$ & $40-44$ & 1.011 & 0.983 & 0.915 & 0.913 \\
\hline $35-39$ & $45-49$ & 0.919 & 0.908 & 0.890 & 0.893 \\
\hline $40-44$ & $50-54$ & 0.902 & 0.910 & 0.840 & 0.872 \\
\hline $45-49$ & $55-59$ & 0.823 & 0.882 & 0.816 & 0.899 \\
\hline $50-54$ & $60-64$ & 0.775 & 0.921 & 0.750 & 0.844 \\
\hline $55-59$ & $65-69$ & 0.730 & 0.782 & 0.678 & 0.776 \\
\hline $60+$ & $70+$ & 0.388 & 0.454 & 0.395 & 0.479 \\
\hline
\end{tabular}

Note: ${ }^{a}$ The 1969 population was moved from January 10,1969 , the date of the census, backward to January 5 , 1969, defining hence an exact interval of 10 years.

\section{Census-based indirect mortality estimations}

In a population closed to migration and with accurate census enumerations, intercensal mortality can be estimated indirectly from two successive age and sex structures. The rationale and methods of the intercensal mortality estimation are based on the survival ratios for five-year age groups from one census to the next. The indirect mortality estimation methods applied here are the variable $r$ method, and the cumulation and projection technique, which both demand only a population distribution from two successive censuses without requiring any other additional estimates of age-specific mortality (for example, number of deaths). 


\subsection{Variable $\mathbf{r}$ method}

Survival conditions of a population can be deduced from two population age distributions. One method, known as the Preston-Bennett method or variable $r$ method, requires only two successive census age distributions classified by the same age groups. Using age-specific growth rates $(r)$, intercensal mortality is directly estimated from the data without passing by a life table system or assumption of population stability. This is desirable in application to developing countries with changing mortality and fertility (such as Mongolia). It is applicable whatever the length of intercensal period and, since this census-based method does not require information on registered deaths (which can be affected by misreporting of age at death), it is not an approach sensitive to age heaping but to age distortions produced by differential census enumeration and intercensal net migration.

From two age distributions, age-specific growth rates are estimated before being applied to population age structure in order to compute the stationary population in interval $\left.{ }_{5} L_{x}\right)$ and then construct abridged life tables. The idea is that "one may relate the number of persons in any two age groups at time $t$ to each other by referring to agespecific mortality conditions and growth rates between those ages over the past year." (Preston and Bennett 1983: 92). The details and the application of the technique have been elaborated elsewhere (Preston and Bennett 1983, Preston et al. 2001, United Nations 1983, 2002).

Tables 3 and 4 present the application of this indirect procedure to Mongolian population for both intercensal periods (1969-79 and 1979-89) with the corresponding interpolated West mortality level (Coale and Demeny 1983) ${ }^{12}$ implied by the estimated life expectancy at age $\mathrm{x}\left(e_{x}\right)$. The set of these estimated $e_{x}$ follows an expected smooth and declining trend with age, indicating that the estimates are fairly consistent.

However, the UN (2002) advise to translate the estimated implied mortality model levels into a common mortality indicator. If these results are translated to life expectancy at age $5\left(e_{5}\right)$ (not shown in Tables, but on Figure 2), an important difference in terms of the implied $e_{5}$ appears. The values of $e_{5}$ range from 50.4 to 64.6 for males and from 55.2 to 67.3 for females in 1969-79 and from 51.9 to 60.3 for males and from 55.9 to 63.9 for females in 1979-89 (Figure 2). In 1969-79, the $e_{5}$ estimates decrease regularly and almost linearly for both sexes, showing no consistency between age groups. The mortality levels implied by the $e_{5}$ values are substantially lower between the younger age groups and the older ones. In 1979-89, albeit variations, the $e_{5}$ outline more consistency.

\footnotetext{
${ }^{12}$ The UN Far Eastern model of mortality has not been selected due to several critics (Zhao 2003, 2004, 2007).
} 
Spoorenberg: What can we learn from indirect estimations on mortality in Mongolia, 1969-1989?

Table 3: Application of the variable $r$ method on smoothed data for estimating intercensal mortality by sex, Mongolia 1969-79

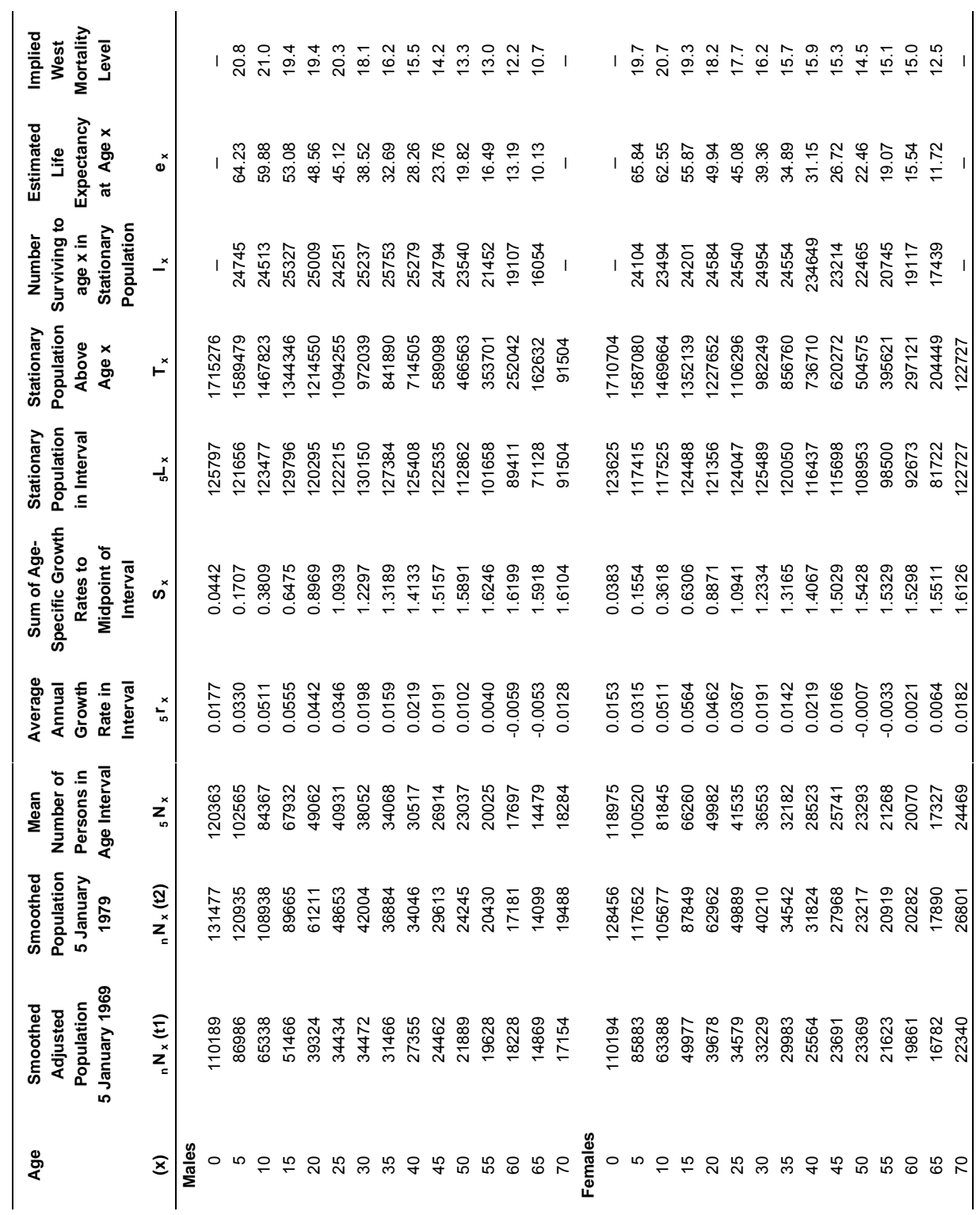


Table 4: Application of the variable $r$ method on smoothed data for estimating intercensal mortality by sex, Mongolia 1979-89

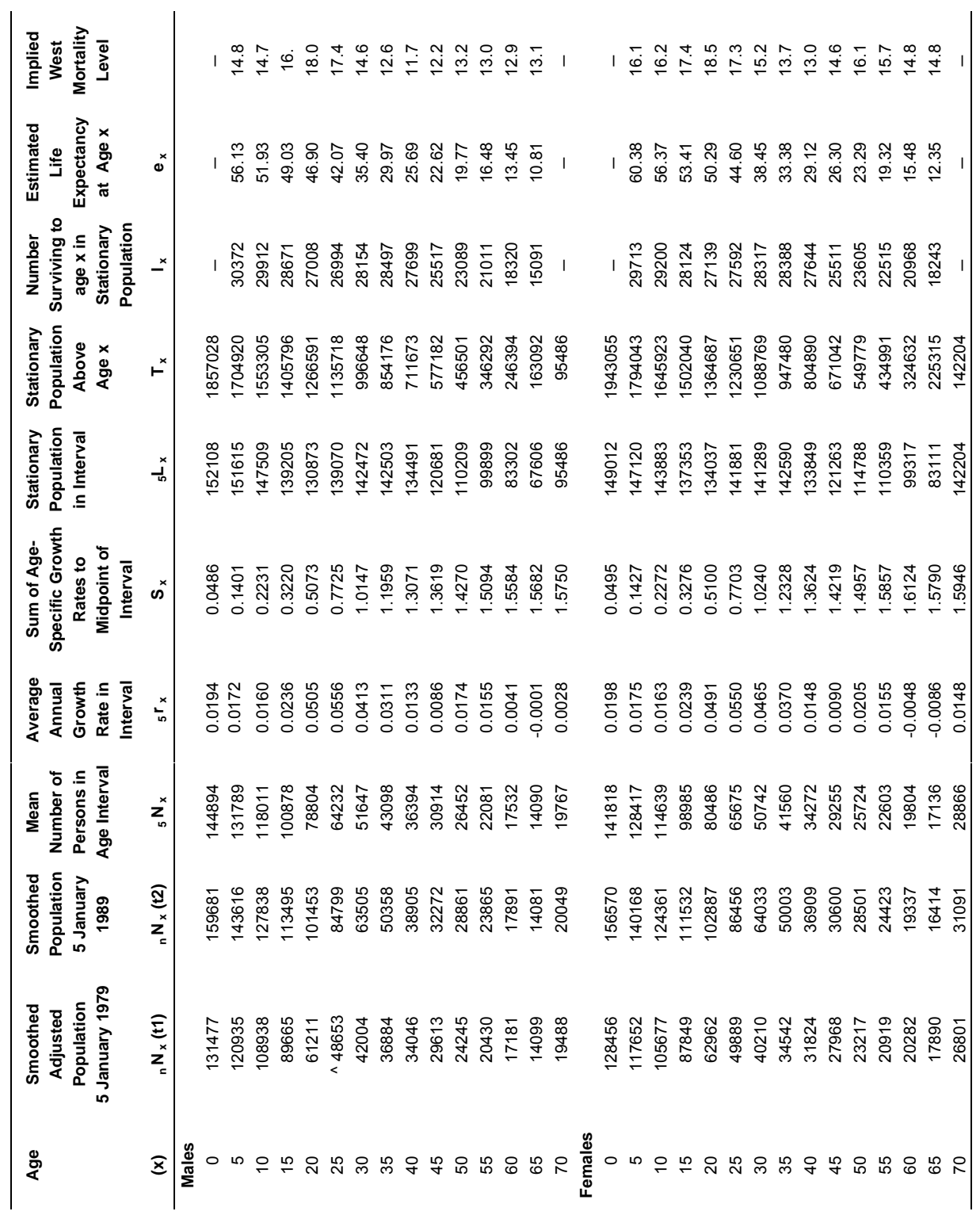


Among these estimated $e_{5}$, the median can be taken as a synthetic measure for mortality level the during intercensal period in Mongolia. Additionally, the half of the inter-quartile range expressed in per cent of the estimated $e_{5}$ is a useful indicator of the relative error associated with the distribution of the $e_{5}$ values (United Nations 2002: 10). Both of these values are shown in brackets in the Figure's caption.

The relative error (half of the inter-quartile range in per cent) reaches 3.8 per cent for females and 6.6 per cent for males in 1969-79. They are high compared to the more consistent implied mortality estimates of 1979-89, resulting in relative error of 1.8 per cent for females and 2.8 per cent for males. However, the 1979-89 implied $e_{5}$ profiles between sexes experience a rise for young adult age groups (15-29 years) and a drop for adult age groups (30-49 years).

Figure 2: Implied West model life expectancy at age $5\left(e_{5}\right)$ resulting from the application of the variable $r$ method on smoothed data, Mongolia, intercensal periods 1969-79 and 1979-89

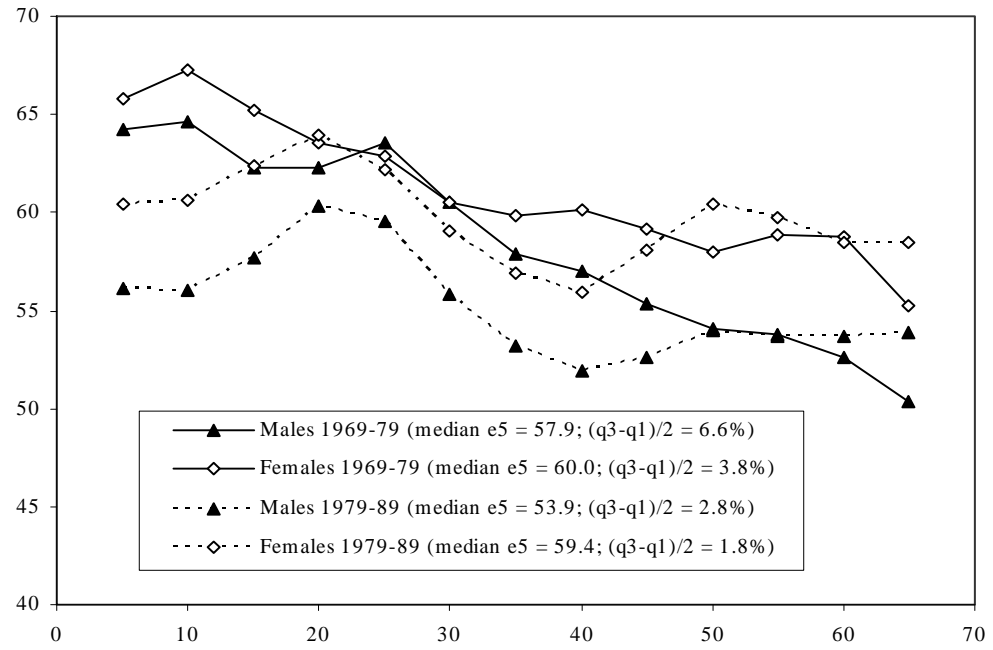

Note: $\left(\mathrm{q}_{3}-\mathrm{q}_{1}\right) / 2$ is the half of the inter-quartile range in per cent of the estimated $e_{5}$

The median estimated $e_{5}$ reaches 57.9 years for males and 60.0 years for females in 1969-79 against 53.9 years and 59.4 years, respectively, ten years later in 1979-89. Based on these results the health conditions of Mongolian population deteriorated during the course of the 1980s and more importantly for males. 
How do the levels and trends of these indirect life expectancy's estimates compare to other estimates? If the values computed for 1969-79 could be considered as realistic, in contrast the 1979-89 values seem unusually low, witnessing a sharp deterioration in the health situation of Mongolian men. Comparison with another indirect mortality estimation is conducted in order to assess the results obtained through the variable $r$ method.

\subsection{Cumulation and projection technique for intercensal mortality estimation}

This projected survivors technique also leads to estimate the general level of intercensal mortality and requires in addition, only an age distribution from two censuses (Arriaga et al. 1994, Palloni and Kominski 1984, Preston et al. 2001, United Nations 1983). This method presents the advantage of eliminating part of the effect of age misreporting by cumulating the age distribution. Only the age distribution from the second census is cumulated by summing downward the uppermost age group until the 5-9 age group (in case of 5-year census interval) or 10-14 age group (in case of 10-year census interval); the first age distribution is not cumulated. Relying on projection technique, it does not compute survival ratios for an intercensal period - as does the variable $r$ method - but projects the population of the earlier census to the date of the latter one. Projected and enumerated populations are thus compared using a range of survival probabilities taken from life tables system. This method can be applied not only to forward projection, but also to reverse/backward projection; the second census in the forward method becoming the first one in the backward projection, and the age distribution is downward summed from the penultimate (in case of 5-year census interval) or the antepenultimate (in case of 10-year census interval) uppermost age group to the 0-4 age group. Due to different errors in age distributions in the two censuses, forward and backward procedures may produce distinct results (Palloni and Kominski 1984). Results obtained from both projections can be compared and averaged in order to attain a final estimate.

This procedure is applied to smoothed Mongolian population structures. Census data from1969 and 1979 are forward-projected in order to obtain 1979 and 1989 enumerated populations. In contrast, 1979 and 1989 age and sex distributions are backward projected in order to obtain 1969 and 1979 enumerated populations. By doing so, different morality levels are estimated. As our aim is to assess the results of the variable $r$ method, Coale and Demeny West model life tables are selected to guarantee comparison consistency.

Table 5 presents the implied West mortality levels obtained through forward and backward projections, and the average final estimation for 1969-79 and 1979-89. Implied West mortality levels contrast between the forward and the backward 
Spoorenberg: What can we learn from indirect estimations on mortality in Mongolia, 1969-1989?

projections. As the age distribution is cumulated only for one census, the effects of errors in age are different and give distinct results.

Table 5: Implied West mortality levels resulting from the application of the cumulation and projection technique on smoothed data for estimating intercensal mortality by sex, Mongolia 1969-79 and 1979-89

\begin{tabular}{|c|c|c|c|c|c|c|c|c|}
\hline \multirow{3}{*}{ Age } & \multicolumn{4}{|c|}{ Implied West Mortality Level } & \multicolumn{2}{|c|}{$\begin{array}{c}\text { Average West Mortality } \\
\text { Level }\end{array}$} & \multicolumn{2}{|c|}{$\begin{array}{c}\text { Estimated Life Expectancy } \\
\text { at Age } 5\end{array}$} \\
\hline & \multicolumn{2}{|c|}{$1969-79$} & \multicolumn{2}{|c|}{$1979-89$} & \multirow{2}{*}{$1969-79$} & \multirow{2}{*}{ 1979-89 } & \multirow{2}{*}{ 1969-79 } & \multirow{2}{*}{ 1979-89 } \\
\hline & Forward & Backward & Forward & Backward & & & & \\
\hline \multicolumn{9}{|l|}{ Male } \\
\hline 0 & - & 23.1 & - & 17.8 & - & - & & \\
\hline 5 & - & 23.3 & - & 17.7 & - & - & & \\
\hline 10 & 22.8 & 22.5 & 17.1 & 19.0 & 22.6 & 18.0 & 67.4 & 60.4 \\
\hline 15 & 22.9 & 23.5 & 16.7 & 20.5 & 23.2 & 18.6 & 68.5 & 61.2 \\
\hline 20 & 22.0 & 24.2 & 18.1 & 21.4 & 23.1 & 19.7 & 68.2 & 62.8 \\
\hline 25 & 23.1 & 23.3 & 19.6 & 20.2 & 23.2 & 19.9 & 68.4 & 63.0 \\
\hline 30 & 23.9 & 22.4 & 20.7 & 19.0 & 23.2 & 19.8 & 68.4 & 62.9 \\
\hline 35 & 22.8 & 22.2 & 19.1 & 19.6 & 22.5 & 19.3 & 67.1 & 62.2 \\
\hline 40 & 21.6 & 22.6 & 17.5 & 21.1 & 22.1 & 19.3 & 66.4 & 62.1 \\
\hline 45 & 21.4 & 23.5 & 17.9 & 22.6 & 22.4 & 20.3 & 67.0 & 63.5 \\
\hline 50 & 21.8 & 24.7 & 19.4 & 24.5 & 23.2 & 21.9 & 68.5 & 66.1 \\
\hline 55 & 22.8 & $>25$ & 20.5 & $>25$ & - & - & & \\
\hline 60 & 24.3 & $>25$ & 23.8 & $>25$ & - & - & & \\
\hline 65 & - & - & - & - & - & - & & \\
\hline 70 & - & - & - & - & - & - & & \\
\hline Median & & & & & & & 68.2 & 62.8 \\
\hline$\left(q_{3}-q_{1}\right) / 2$ per cent & & & & & & & 0.95 & 0.74 \\
\hline \multicolumn{9}{|l|}{ Female } \\
\hline 0 & - & 24.2 & - & 21.3 & - & - & & \\
\hline 5 & - & $>25$ & - & 22.0 & - & - & & \\
\hline 10 & 23.6 & 24.1 & 20.4 & 23.5 & 23.9 & 21.9 & 73.0 & 69.4 \\
\hline 15 & $>25$ & $>25$ & 21.0 & 24.2 & $>25$ & 22.6 & 75.4 & 70.6 \\
\hline 20 & 24.4 & $>25$ & 22.6 & 24.5 & 24.7 & 23.6 & 74.8 & 72.4 \\
\hline 25 & 24.6 & 24.8 & 23.4 & 24.1 & 24.7 & 23.8 & 74.7 & 72.8 \\
\hline 30 & 24.6 & 24.8 & 23.8 & 24.0 & 24.7 & 23.9 & 74.7 & 73.1 \\
\hline 35 & 24.3 & $>25$ & 23.2 & $>25$ & 24.6 & 24.1 & 74.6 & 73.5 \\
\hline 40 & 24.2 & $>25$ & 23.0 & $>25$ & 24.6 & 24.0 & 74.6 & 73.3 \\
\hline 45 & 24.8 & $>25$ & 23.3 & $>25$ & 24.9 & 24.2 & 75.2 & 73.6 \\
\hline 50 & $>25$ & $>25$ & $>25$ & $>25$ & $>25$ & $>25$ & 75.4 & 75.4 \\
\hline 55 & $>25$ & $>25$ & $>25$ & $>25$ & - & - & & \\
\hline 60 & $>25$ & $>25$ & $>25$ & $>25$ & - & - & & \\
\hline 65 & - & - & - & - & - & - & & \\
\hline 70 & - & - & - & - & - & - & & \\
\hline Median & & & & & & & 74.7 & 73.1 \\
\hline$\left(q_{3}-q_{1}\right) / 2$ per cent & & & & & & & 0.35 & 0.75 \\
\hline
\end{tabular}

Note: Only the first nine estimates are shown in Table since it is recommended to take the median among those first nine estimates to obtain a single estimated life expectancy at age $5\left(e_{5}\right)$ (United Nations 1983: 210). Levels over 25 are considered as 25. $\left(q_{3}-q_{1}\right) / 2$ is the half of the inter-quartile range in per cent of the estimated $e_{5}$ 
For each intercensal period, the results are averaged in order to estimate a common mortality indicator (life expectancy at age 5). The half of the inter-quartile range expressed in per cent of the estimated $e_{5}$ can also be used to indicate the relative error associated with the distribution of the estimated $e_{5}$. For both sexes and intercensal periods, the values shown are low, signifying that $e_{5}$ estimates are homogeneous (Table 5). As previously, the median level and its corresponding life expectancy at age $5\left(e_{5}\right)$ are taken as a synthetic measure for estimating intercensal mortality. The estimated $e_{5}$ stands for males at 68.2 years in 1969-79 and 62.8 years in 1979-89, and for females at 74.7 years and 73.1 years, respectively. Albeit different than variable $r$ results, these values point also to a decline in health conditions in Mongolia.

\section{Comparison between indirect methods}

The application of the variable $r$ method and the projection and cumulation technique give different results. Figure 3 plots estimates of life expectancies at age 5 obtained by the application of the two indirect methods. With a difference comprised between 10 and 15 years in estimated $e_{5}$, the results shown are rather dissimilar. In comparison with the variable $r$ method, the final $e_{5}$ estimates resulting from the cumulation and projection technique are higher (with differences even higher in the case of females). These differences can be attributed to both census data quality and choice of model life table, which are the basis of the estimations.

Figure 3: Comparison of life expectancy at age $5\left(e_{5}\right)$ estimates obtained by the application of the variable $r$ method, and cumulation and projection method, Mongolia, intercensal periods 1969-79 and 1979-89

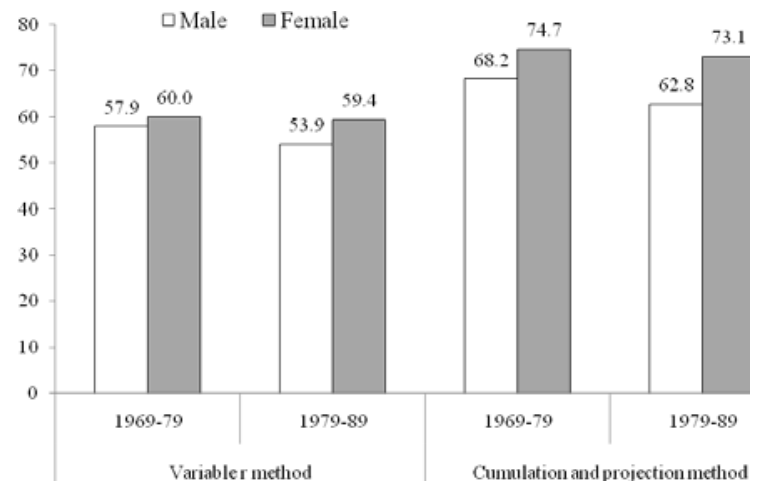


The variable $r$ method is based on the assumption that differential census coverage and rates of emigration are constant by age (Preston and Bennett 1983). But in Mongolia, like in many other populations (Anderson 2004), under-enumeration is concentrated in some age groups. To detect error on age distribution, the translation of the mortality level observed to a common mortality is useful. If the computed $e_{x}$ are coherent and there is no effect of age misstatement, the set of $e_{5}$ should be similar. Here, an under-enumeration of the 0-4 age group in 1969 (Table 2) implies an overestimation of surviving proportion through 1979, yielding a too high $e_{5}$ estimate at age 5 (Figure 2). It is likely that the same occurs for the 5-9 age groups in 1969 (coupled to an over-representation of the 15-19 age group in 1979 compared to adjacent groups), giving a too high $e_{5}$ estimate at age 10 . The same process could have been found at age 15, but since the age group 10-14 is better enumerated in 1969 than the 20-24 age group in $1979, e_{5}$ drops. The peak on age 25 for males mirrors the better enumeration of males aged 30-34 compared to those aged 20-24 ten years earlier. Finally, the relative stagnation of female $e_{5}$ after the age of 30 could be produced by systematic underenumeration of younger age groups in 1969, compared to the ones ten years older enumerated in 1979. Alternatively, it could also picture real pattern, pointing to consistency in implied $e_{5}$. In 1979-89, the under-enumeration at childhood (0-9) has faded (Table 2), resulting in more confident estimated $e_{5}$ at age 5 and 10 . However, the under-enumeration of young adult groups in 1979 (15-29), coupled with better enumeration for adults in 1989, yield the estimated $e_{5}$ values at age 15, 20 and 25 to rise. At adult ages, with better enumeration, $e_{5}$ declines back to more consistent levels. But due to age overstatement at older age - transfer from one age group to the other, which is more distinct for females - the implied $e_{5}$ oscillates. Mongolian censuses present indeed over-representation of some age groups since the age of 40. Starting from that age, the ratio of two successive age groups is systematically higher for the oldest age group $\left({ }_{5} P_{a+5}\right)$, and higher for the age groups ending by 5-9 (Spoorenberg 2007). This pattern is particularly prominent for the 55-59 age group in 1979 and 1989. It results in the lowest estimates of $e_{5}$ at age 40 and higher life expectancies at ages just before 60 (Figure 2).

In the projection and cumulation technique, census data quality and choice of mortality model have also an impact on the final $e_{5}$ estimates. Due to different data quality (female data quality is not as good as male), the differences are higher for females than males. If data suffer from under-enumeration, the (forward or backward) projected population will be close to the enumerated population at the second census. Such bias gives high estimations of implied mortality levels (West model), reflecting low death-risks (or high survivorships) between two censuses. ${ }^{13}$ However, with the

\footnotetext{
${ }^{13}$ In the Coale and Demeny life table system, levels of mortality are classified by female life expectancy at birth from 1 to 25 with an increment of 2.5 years; 25 corresponds to a female life (continued on next page)
} 
amelioration of census data quality, the 1979-89 intercensal mortaliy estimates are more consistent (albeit the female final $e_{5}$ estimate is clearly too high).

Part of those variations can also be attributed to the choice of the model life table. Since each model life table has its own age-specific mortality pattern, a poor choice would affect the estimation of $e_{5}$. Coale and Demeny's West model is used. The West model stands between the North and East patterns which are characterized by (for North) low infant mortality and low old age mortality beyond age 50, and (for East) by high child mortality in relation to infant mortality. (Murray et al. n.d.: 4) Without detailed information on Mongolian age-specific mortality, this residual West model has been used. But it is likely that Mongolian mortality age pattern does not fit with the West mortality pattern. The estimated $e_{5}$ profiles (Figure 2 and Table 5) suggest that the choice of the West model does not completely represent Mongolian mortality pattern. Moreover, among the two methods, the choice of mortality model plays a more important role in the cumulation and projection technique since survival probabilities taken from life table systems are directly used in the projection.

However, in spite of these effects on final estimates, both methods point to and confirm deterioration in health conditions between the 1970s and 1980s affecting both sexes. But females experienced a relative stagnation while males present a significant decline. Of course, the estimated mortality levels suffer from bias of data quality and choice of mortality model, and should not be taken for granted. However, is the stagnating and/or declining trend likely to be real?

The next section confronts the indirect mortality estimates to mortality calculated from the civil registration system (direct method).

\section{Confrontation of indirect estimates with direct mortality computed from civil registration data}

During the socialist period, Mongolia developed a reasonably complete vital registration system of births, deaths, marriages, and population movements. If births and marriages can be considered reliable, migration and mortality are not. Indeed, mortality suffers from under-enumeration mainly in young ages. According to assessment conducted through consistent correction analysis and indirect estimates, infant mortality under-registration is nearly 30 percent in socialist Mongolia (Neupert 1996: 23). ${ }^{14}$

expectancy at birth to 80 years. Hence, high levels of mortality in any models (North, South, East, or West) correspond to low death rates and high life expectancy.

${ }^{14}$ This value is higher than the estimation of 20-25 percent conducted by Anderson \& Silver (1986) for the Soviet republics. 
However, even if infant mortality is under-registered, the published age-specific death rates can be used in order to confront and assure the results obtained by indirect estimates. Indeed, this comparison provides not only an assessment of indirect mortality estimates; it offers also the opportunity to evaluate the quality of the registration of deaths in the civil registration system.

In order to confront the mortality estimates obtained from the application of the two indirect estimations, life expectancies have been directly computed from noncorrected civil registration age-specific death rates. These death rates are published by sex for each five years from 1965 to 2000 (NSO 2003). Six years are used here (1965, $1970,1975,1980,1985$, and 1990) in order to cover the last two decades of the socialist period and to assure a fairly reliable comparison with indirect mortality estimates. The indirect estimates are computed for a 10-year period (1969-79 and 1979-89). To ease the comparison, they have been centred on the mid-period year (1974 and 1984, respectively).

The confrontation of the life expectancy at age $5\left(e_{5}\right)$ from the two indirect mortality estimations and the direct mortality computation gives quite satisfactory results (Figures 4 and 5). The declining mortality trend for both men and women (with sharper male decline) is also found with the application of the direct method. Moreover, the direct $e_{5}$ are comprised between the two indirect estimates. Real mortality levels and trends are likely to be found between the two indirect estimations.

Figure 4: Confrontation of male life expectancy at age $5\left(e_{5}\right)$ resulting from the application of two indirect estimations and a direct estimation based on civil registration data.

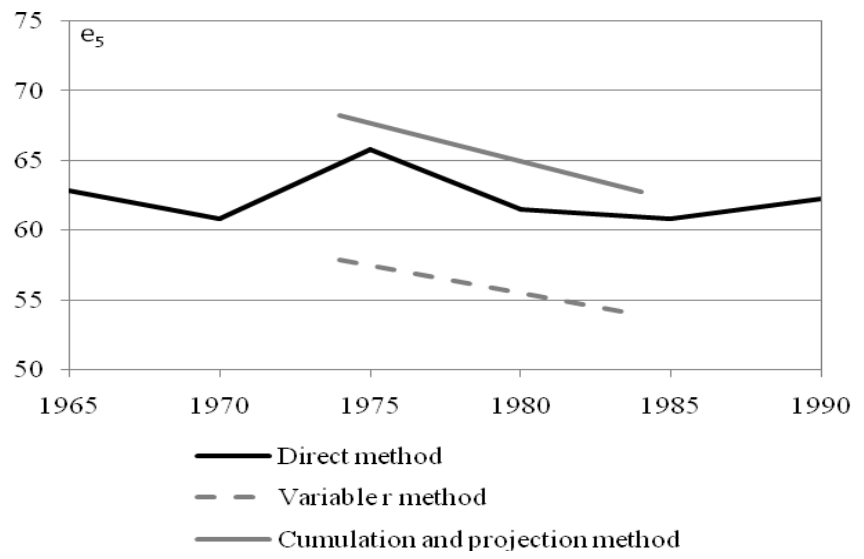

Note: civil registration data not corrected. 
Figure 5: Confrontation of female life expectancy at age $5\left(e_{5}\right)$ resulting from the application of two indirect estimations and a direct estimation based on civil registration system data.

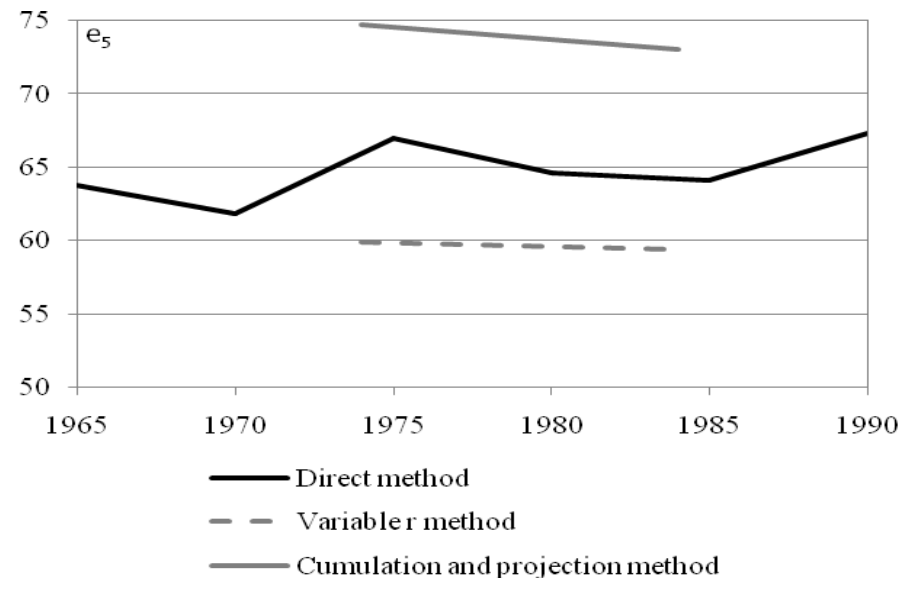

Note: civil registration data not corrected.

As census data quality is better for men than for women during socialist time, the indirect mortality estimations are closer to reality for men than for women (Spoorenberg 2007). For the former, between the two indirect estimations, the cumulation and projection method gives quite close mortality estimation to reality (direct method). For women, both indirect methods (based on worse census data quality) are relatively distant from reality. However, civil registration data are not corrected. The direct $e_{5}$ are hence over-estimated, since infant mortality is underregistered in civil registration system. ${ }^{15}$

The confrontation of indirect mortality estimations with direct mortality computation corroborates and gives confidence in a declining trend. This pattern raises the assumption of a common mortality trajectory to all the former socialist countries. The deterioration in the health situation of the Mongolian population paralleled the experience found elsewhere.

\footnotetext{
${ }^{15}$ The contribution of infant mortality in mean duration of life is generally high when life expectancy is low.
} 


\section{Putting Mongolian health situation in perspective}

The deterioration in health conditions of the Mongolian population during the course of the 1970s and 1980s is consistent with mortality evolution found in and documented for the countries of the former USSR (Baltic States, Russia, Ukraine, Kazakhstan...) and Eastern Europe (Bulgaria, the Czech Republic, Hungary, Poland, Romania, Slovakia). Since the 1960s these countries underwent a steady long-term decline in male life expectancy at birth and a relative stagnation in female life expectancy at birth, increasing the sex-inequality in health (Meslé and Vallin 2003, 2006; Shkolnikov et al. 2004). Added to these experiences, Mongolian indirect mortality estimates raise the hypothesis of a Soviet or socialist mortality pattern since countries with different socioeconomic situations present rather similar mortality experiences.

At the $11^{\text {th }}$ Congress of the MAHN in 1948, the First Five-Year Plan was launched with the aim to develop a national centralized economy, mainly based on industrialization and collectivisation of the agricultural sector. This was the real first step toward modernization of Mongolia (Neupert 1996). With the collectivisation of the economy, the health infrastructures developed significantly. ${ }^{16}$ Substantial improvements in health (development of public health system, importation of modern medical technology from the Soviet Union), education, and general living standard contributed to significant mortality decline from the end of the 1940s (Neupert 1996; Randall 1993; Riley 2005).

As a USSR satellite, the health system that Mongolia implemented was very similar to the Soviet organization. The Mongolian health care system was free of charge and with the aim of total regional coverage. It was articulated between different levels in order to reach both rural nomadic and urban population. In Mongolia, as in other socialist countries, the gains over death were impressive during the first decades, but the system was unable to guarantee sustained gains in life conditions.

The consequences of the collapse of the USSR on mortality has recently benefited from numerous studies. ${ }^{17}$ Even if these studies focused on the recent mortality increase, and that the causes underlying these mortality changes are relatively complex, they give useful insight to understand the deterioration of life conditions that took place since the 1960s. Among the various possible causes of health deterioration since the 1960s, the one considering the health system and its consequences for the conception of individual and health is the more plausible, because of its consistency and broadness.

\footnotetext{
${ }^{16}$ For an account of health sector development both before and after the 1940s, see Neupert 1996: 58. During the 1960s, the number of doctors per ten thousand population increased from 9.7 to 17.9 and the number of hospitals from 68 to 112 (Randall 1993: 218).

${ }^{17}$ An international seminar - Mortality in the former USSR. Fifteen years after the break-up: Change or continuity? - has been devoted to this issue in 2006.
} 
With the exception of the countries having experienced mortality changes due to war, AIDS, or natural disasters, all the countries experiencing health deterioration over the last 40 years shared a common socialist organization. Among all these former socialist countries (and Mongolia as well), a paternalist conception based on the idea of societal responsibility for the health of the population prevailed (Neupert 1996). In a socialist system, people are taught to 'sacrifice' themselves for the benefit of the society. In reward, the State offers and grants free access to a series of social services including maternity, child, and family allowances, pensions for the elderly, education, employment, access to health care... Such a paternalist system has many implications for the conception people have of themselves and the notion of health. As Shkolnikov et al. wrote (2004: 66 quoting Nazarova 2000), "[o]ne consequence was the creation of a culture in which it was felt that there was little that individuals could do to protect their own health.” In other words, the individual life and health were ranked low in comparison to the final goal: a socialist society. ${ }^{18}$

Coupled with defective preventive medicine (and poor quality medical services), these conceptions have a dramatic effect in the face of epidemiological transition. With the change from infectious to chronic diseases (which require more preventive treatment), the former paternalist Soviet health system had little effect. Whereas the Soviet health system was quite effective in tackling infectious diseases, it remained inefficient once the successes over infectious diseases were realized and chronic diseases increased. ${ }^{19}$ Indeed, the conception of the individual and health required to face these two categories of diseases are completely different. To contend with chronic diseases presupposes a different health-habitus ${ }^{20}$ than with infectious diseases. But the health-habitus (i.e. socially accepted reasons and moment in the progression of symptoms and illness to attend health facilities...) people acquired during socialist times is no longer in phase with the new epidemiological context. The epidemiological transition and the inability of the people to react properly to the new epidemiological situation, added to financial difficulties to maintain and refurbish the health facilities due to an increasing demand and/or other priorities, explains largely the deterioration of health conditions across all socialist countries since the 1960s. Moreover, in the case of Mongolia, the collectivisation process has been accompanied by the sedentarisation of the population, implying that the past epidemiological advantages of mobility decreased. It is likely that the disease pattern experienced a change, "with decrease in the incidence or severity of easily treatable diseases and an increase in those linked with

\footnotetext{
${ }^{18}$ This is even more exacerbated in a context of rivalry with the West.

${ }^{19}$ Research showed that the decline in 'avoidable mortality' (from causes amenable to timely and effective health care) had been a quarter to a third slower in Eastern European countries than in Western European countries during the 1970s and 1980s (Nolte et al. 2005: 167).

${ }^{20}$ The concept of habitus is based on the work of Pierre Bourdieu and can be understood as a lasting system of dispositions, actions, or perceptions acquired through socialization and social experiences.
} 
sanitation” (Randall 1993: 219). In the face of this new epidemiological situation, the past traditional health-habitus were useless as well.

The explanation retained here is of course not complete, however, it offers a consistent and broad account of the deterioration of health conditions found from the 1960s, in various socio-economic and geographic countries, all sharing a common feature: socialism.

\section{Conclusion}

In the absence of studies on mortality during the socialist period in Mongolia, this paper has proposed the use of indirect census-based techniques to estimate mortality levels and trends. It gives only a first, very rough insight on what happened to mortality in Mongolia during the last decades of its socialist period. The indirect mortality estimations indicate a declining trend in life expectancy. This result is quite reliable since direct method based on not corrected civil registration data corroborates also this decline. However, as the two indirect estimates show, mortality levels are quite inconsistent.

Mongolian mortality exhibits similar declining/stagnating trends as other socialist countries. It is likely that the health system, common to all these countries, has played a key role in the deterioration of the population's health conditions. The conception of the individual and health at the core of the system is not in phase when infectious diseases give way to chronic diseases. Not only is the health system not ready to face the new epidemiological challenge, the people with their integrated health-behaviors (healthhabitus) find it also difficult to adapt. In Mongolia, the collectivisation taking place in a nomadic society implied the sedentarisation of a large band of the population. The past advantages of mobility are no longer effective, with a new disease pattern linked to sedentarised lifestyle. The inherited traditional health-habitus is no longer effective and adds additional difficulties to the adaptation of population.

As this paper addressed only general levels and trends in Mongolia, there is a need to gain more in-depth understanding about mortality in both socialist and post-socialist Mongolia. This next step should deal with more precise analysis of mortality levels and trends in Mongolia, by studying both the general mortality and the age-specific mortality in order to consider whether the Mongolian population has been exposed to the same mortality risks as other socialist populations (for example significant increase in male adult mortality). Similarly, in doing so, the cause-specific mortality should also be addressed. Such endeavors must be based on civil registration data. However, there is need to first concentrate more specifically on the issue of data quality before carrying 
out studies on mortality in Mongolia and consider whether the equivalent "socialist mortality patterns” are found as well.

\section{Acknowledgments}

The author would like to thank Ricardo Neupert for his valuable comments and suggestions, Yvonne Sandor for her language editing, and Renée Flibotte-Lüskow of the editorial office for her kind assistance throughout the review and edition process. 


\section{References}

Anderson, B.A. (2004), “Undercount in China's 2000 census in comparative perspective”, Ann Arbor, University of Michigan, Population Studies Center, PSC Research Report No. 04-565.

Anderson, B.A. and Silver, B.D. (1986) "Infant mortality in the Soviet Union: Regional differences and measurement issues", Population and Development Review, 12(4), pp. 705-738.

Arriaga, E.E., Johnson, P.D. and Jamison, E. (1994), Population Analysis with Microcomputers. Vol. 1, Presentation of Techniques, Washington D.C., US Bureau of the Census.

Atwood, C.P. (2004), Encyclopedia of Mongolia and the Mongol Empire, New York, Facts on File.

Baabar, B. (B. Batbayar) (2005), History of Mongolia, transl., Cambridge, University of Cambridge, The Mongolian and Inner Asia Studies Unit (first published in 1999).

Bawden, C.R. (1989), The Modern History of Mongolia, $2^{\text {nd }}$ revised ed., London, Keegan Paul International.

Coale, A., Demeny, P. and Vaughan, B. (1983), Regional Model Life Tables and Stable Populations, Second edition, New York, Academic Press.

Dashtseren, A. (2002), "Determinants of infant and child mortality in Mongolia”, Paper presented at the IUSSP Regional Conference on Southeast Asia's Population in a Changing Asian Context, Bangkok, Thailand, 9-13 June 2002, 25 p.

Janes, C.R. and Chuluundorj, O. (2004), "Free markets and dead mothers: The social ecology of maternal mortality in post-socialist Mongolia", Medical Anthropology Quarterly, 18(2), pp. 230-257.

Kaplonski, C. (2003), Truth, History and Politics in Mongolia. The Memory of the Heroes. London, RoutledgeCurzon.

Legrand, J. (1997), Parlons Mongol, Paris, L’Harmattan.

Meslé, F. and Vallin, J. avec des contributions de Shkolnikov V., Pyrozhkov S., Adamets S. (2003), Mortalité et causes de décès en Ukraine au XX siècle, Paris INED, les cahiers de l’Ined, ${ }^{\circ} 152$. 
Meslé, F. and Vallin J. (2006), "Interpreting recent mortality changes in the former USSR in the light of long terms trends and reference to Central Europe", in Mortality in the Former USSR. Fifteen Years after the Break-up: Change or Continuity?, International seminar, Kiev 12-14 October 2007, Working papers, vol. 2, pp. 68-88.

Murray, C.J.L., Ahmad, O.B., Lopez, A.D. and Salmon, J.A. (n.d.), WHO System of Model Life Tables, WIP/GPE/EBD, World Health Organization, GPE Discussion Paper Series No. 8.

Neupert, R.F. (1992), "Mongolia: Recent demographic trends and implications”, AsiaPacific Population Journal, 7(4), pp. 3-24.

Neupert, R.F. (1995), "Early-age mortality, socio-economic development and the health system in Mongolia”, Health Transition Review, 5, pp. 35-57.

Neupert, R.F. (1996), Population Policies, Socioeconomic Development and Population Dynamics in Mongolia, Canberra, Australian National University, Research School of Social Sciences.

Nolte, E., McKee, M. and Gilmore, A. (2005), "Morbidity and mortality in the transition countries of Europe", in M. Macura, A.L. MacDonald and W. Haug (eds), The New Demographic Regime. Population Challenges and Policy Responses, New York/Geneva, United Nations

NSO (National Statistical Office of Mongolia) (2002), Population Projections of Mongolia. Analysis based on the 2000 Census, Ulaanbaatar, National Statistical Office.

NSO (National Statistical Office of Mongolia) (2003), Mongolian Population in XX Century, Ulaanbaatar, National Statistical Office.

Palloni, A. and Kominski, R. (1984), "Estimation of adult mortality using forward and backward projections”, Population Studies, 38(3), pp. 479-493.

Pandey, R. N. (1997), "Levels and patterns of infant and child mortality in Mongolia", Asia-Pacific Population Journal, 12(3), pp. 49-64.

Preston, S.H. and Bennett, N.G. (1983), “A census-based method for estimating adult mortality”, Population Studies, 37(1), pp. 91-104.

Preston, S.H., Heuveline, P. and Guillot, M. (2001), Demography, Measuring and Modelling Population Processes, Oxford, Blackwell. 
Randall, S. (1993), "Issues in the demography of Mongolian nomadic pastoralism”, Nomadic Peoples, 33, pp. 209-239.

Riley, J.C. (2005), "The timing and pace of health transitions around the world", Population and Development Review 31(4): 741-764 and the bibliography of more than 700 sources published separately on the Web at http://www.lifetable.de/RileyBib.htm.

Shkolnikov, V.M., Andreev, E.M., Leon, D.A., McKee, M., Meslé, F., and Vallin, J. (2004), "Mortality reversal in Russia: The story so far", Hygiea Internationalis, vol. 4, no. 4, pp. 29-80.

Spoorenberg, T. (2007), “Age and sex structure of the population of Mongolia. An evaluation of the population censuses of Mongolia, 1956-2000", Mongolian Population Journal, 16, pp. 118-134.

United Nations (1983), Manual X: Indirect Techniques for Demographic Estimation, New York, Department of International Economic and Social Affairs, Population Studies $\mathrm{n}^{\circ} 81$.

United Nations (2002), Methods for Estimating Adult Mortality, New York, Population Division, Department of Economic and Social Affairs, ESA/P/WP.175.

Zhao, Z. (2003), “On the Far Eastern pattern of mortality”, Population Studies, 57(2), pp. 131-147.

Zhao, Z. (2004), "The Far Eastern pattern of mortality is not a unique regional mortality model: A reply to Noreen Goldman”, Population Studies, 58(1), pp. 121-124.

Zhao, Z. (2007), "The interpretation and use of the United Nations 1982 Model Life Tables: With particular reference to developing countries”, Population-E, 62(1), pp. 89-117.

Zhao, Z. and Kinfu, Y. (2005), "Mortality transition in East Asia", Asian Population Studies, 1(1), pp. 3-30. 